Research Article

\title{
Fixed dose combinations- to prescribe or not to prescribe: a dilemma of medical profession
}

\author{
Mayank Prakash Nigam*, Vinson L. G. Fernandes, Padmanabh V. Rataboli
}

Department of Pharmacology,

Goa Medical College,

Bambolim- 403201, Goa, India

Received: 27 November 2013

Revised: 5 December 2013

Accepted: 11 December 2013

\section{*Correspondence to:}

Mayank Prakash Nigam,

Email: maynigam@gmail.com

(C) 2014 Nigam MP et al. This is an open-access article distributed under the terms of the Creative Commons Attribution Non-Commercial License, which permits unrestricted non-commercial use, distribution, and reproduction in any medium, provided the original work is properly cited.

\begin{abstract}
Background: Fixed dose combinations (FDCs) refer to products containing two or more ingredients used for a particular indication in a single dosage form. Prescribing FDCs has become a routine affair in medical practice. There has been increase in the irrational FDCs in the recent past by leaps and bounds. The pharmaceutical companies are luring the physicians to prescribe their products even when they are not needed by the patients. The Indian laws too are not properly defined to grant marketing approvals of FDCs. Hence the rationality of a FDC has become one of the most controversial and debatable issues in general practice.

Methods: We hence decided to analyze the existing FDCs in Indian market and study their rationality.

Results: We observed that, although many brands of FDCs available are essentially rational as per WHO and Indian essential drugs lists, the irrational FDCs easily outnumber the rational ones. Hundreds of rational FDCs are also available which are not included in WHO or Indian essential drugs lists. A few FDCs with incorrect doses were also noted. Irrational FDCs not only cause more adverse drug reactions but the antibiotic FDCs are responsible for increasing the chances of resistance. A few of these are discussed for their irrationality.

Conclusions: It is the need of the hour to raise our voice against the growing list of irrational FDCs and try to reduce the magnitude of this problem by sensitizing the undergraduates, the interns as well as the practitioners regarding their efficacy, safety, suitability, rationality and cost benefit.
\end{abstract}

Keywords: Fixed dose combinations, Drug combinations, Irrational combinations, Essential drug combinations, Rational combinations

\section{INTRODUCTION}

Fixed dose combinations (FDCs) refer to products containing two or more ingredients used for a particular indication in a single dosage form. Although it is widely accepted that most drugs should be ideally prescribed as single compounds, prescribing FDCs has become a routine affair in medical practice. Forwarding the argument of better patient compliance, doctors in private as well as government hospitals prescribe a lot of FDCs. ${ }^{1}$ As more and more doctors favour FDCs, the pharmaceutical companies turn to this potential "golden egg" and market more and more combinations, many of them irrational.
Dr. Plianbangchang, Regional Director of WHO, SouthEast Asia region has rightly said - "Medicines are a commodity that is subjected to market forces; it is a highly profitable commodity producing a high rate of return. It is, therefore, understandable why those involved in its production sales would influence the decision as to what medicines are prescribed and sold". Thus, manufacturers continue to reap the benefits of huge sales, and continue to promote such combinations with vigour, even though the practice is unethical and can harm the patient.

The Indian laws are not properly defined to grant marketing approvals of FDCs by State or Central Drug Controlling Authorities. Hence the rationality of a FDC 
has become one of the most controversial and debatable issues in general practice. $^{2}$

The 16th essential medicines list of WHO has 351 essential medicines, including $25 \mathrm{FDCs}^{3}$ whereas the National list of essential drugs of India has 354 essential drugs including 14 FDCs. ${ }^{4}$ Despite of this, hundreds of irrational FDCs are being marketed in India under more than 1,000 brand names. ${ }^{5}$

A pharmaceutical company may develop a FDC with the sole aim of marketing advantage of exclusive rights to sell the FDC, even though the individual active ingredients may be off patent. ${ }^{6}$ Ideally, before marketing such FDCs, the cumulative toxicities and risks benefits of the drugs in combination need to be clinically and pharmacologically evaluated, but this exercise is not always done.

The first genuine attempt to weed out the irrational and harmful combinations of drugs marketed in India was initiated by the Drugs Controller General of India (DCGI) in 2007 when he directed State Drug controllers (SDCs) to withdraw 294 FDCs from the market. The order could not be enforced as the drug companies opposed the move and challenged it in Madras High Court. The case has not been settled till date.

In January 2013, the office of the DCGI issued a fresh directive to the manufacturers asking them to prove the safety and efficacy of FDCs approved before October 2012 and all those FDCs approved by the SDCs after October without the permission of the DCGI. If not compliant, the said FDCs were supposed to be considered for the ban. However, licences for new FDCs continue to be issued by the SDCs in violation of the Drugs and Cosmetics act, and the Madras High Court is yet to decide on the 294 FDCs.

Expert committee set up by the Central Drugs Standard Control Organization (CDSCO) for formulating the policy on FDCs concluded its first meeting in New Delhi on March 4, 2013. This meeting, a first of its kind is seen as an important development in formulating the much needed strict guidance document for approval of FDCs in India. $^{7}$

Considering these facts and figures, we decided to analyze the existing FDCs in Indian market and study their rationality. The study was planned with the aim of creating evidence-based awareness in practicing doctors who are misled by the pharmaceutical representatives.

\section{METHODS}

We noted down the various FDCs listed in CIMS, MIMS, IDR and Drug Today and also visited the local pharmacies to get more names of FDCs which do not figure in these books. These FDCs were then analyzed and grouped under the following categories.

1. Rational FDCs approved by WHO

2. Rational FDCs included in the most recent Indian essential drugs list

3. Rational FDCs which are pharmacologically correct in combinations but not included in WHO or Indian essential drugs lists: The rationality of these FDCs was determined by reviewing the available literature, which included the standard reference books in Pharmacology (The Pharmacological basis of Therapeutics, Martindale) and published medical articles which revealed evidence of benefit in combination.

4. FDCs which are pharmacologically irrational: The FDCs were considered as irrational if they did not follow the accepted rules for drugs in combination (8).

5. FDCs which are totally absurd: These included a few FDCs labeled as 'absurd' and totally unfit for use by the Indian drug authorities, and which are now discontinued. These FDCs are totally weird with no scientific basis of combination.

6. Rational FDCs which are rational or irrational but with incorrect doses: The correctness of doses was determined by referring to standard textbooks in Pharmacology.

Our main focus in this study is, unlike in most of the publications on FDCs, to acknowledge the readers about the scientific reasons behind the claims of irrationality, and to put forth data-based evidence for a number of FDCs which can be safely and rationally used in clinical practice.

\section{RESULTS}

Although many brands of FDCs available in Indian market are essentially rational as per WHO and Indian essential drugs lists (Table 1 and Table 2), the irrational FDCs easily outnumber the rational ones. Hundreds of rational FDCs are also available which are not included in WHO or Indian essential drugs lists. A few FDCs with incorrect doses were noted.

List of FDCs which are pharmacologically correct but not included in standard drugs lists (Table 3). Data shows commonly used irrational FDCs and a few FDCs labeled as absurd by the drug authorities and advised discontinuation respectively (Table 4 and Table 5). 
Table 1: FDCs included in the $16^{\text {th }}$ WHO model list of essential medicines.

\begin{tabular}{|ll|}
\hline Sr. No. & Combination \\
\hline 1. & Benzoic acid + Salicylic acid \\
\hline 2. & Carbidopa + Levodopa \\
\hline 3. & Sulfamethoxazole + Trimethoprim \\
\hline 4. & Pyrimethamine + Sulfadoxine \\
\hline 5. & Ethinylestradiol + Levonorgestrel \\
\hline 6. & Neomycin + Bacitracin \\
\hline 7. & Isoniazid + Rifampicin \\
\hline 8. & Ferrous salt + Folic acid \\
\hline 9. & Amoxycillin + Clavulanic acid \\
\hline 10. & Artemether + Lumefantrine \\
\hline 11. & Efavirenz + Emtricitabine + Tenofovir \\
\hline 12. & Ethinylestradiol + Norethisterone \\
\hline 13. & Imipenem + Cilastatin \\
\hline 14. & Lignocaine + Epinephrine \\
\hline 15. & Isoniazid + Rifampicin + Pyrazinamide \\
\hline 16. & Isoniazid + Ethambutol \\
\hline 17. & Isoniazid + Rifampicin + Pyrazinamide + Ethambutol \\
\hline 18. & Medroxyprogesterone acetate + Estradiol cypionate \\
\hline 19. & Isoniazid + Rifampicin + Ethambutol \\
\hline 20. & Lamivudine + Zidovudine \\
\hline 21. & Emtricitabine + Tenofovir \\
\hline 22. & Lamivudine + Zidovudine + Nevirapine \\
\hline 23. & Lamivudine + Stavudine + Nevirapine \\
\hline 24. & Lopinavir + Ritonavir \\
\hline 25. & $\begin{array}{l}\text { Oral Rehydration Salts (sodium chloride, trisodium } \\
\text { citrate, potassium chloride, glucose) }\end{array}$ \\
\hline
\end{tabular}

Table 2: FDCs included in the national essential medicines list of India.

\begin{tabular}{|ll|}
\hline Sr. No. & Combinations \\
\hline 1. & Benzoic acid + Salicylic acid \\
\hline 2. & Carbidopa + Levodopa \\
\hline 3. & Sulfamethoxazole + Trimethoprim \\
\hline 4. & Pyrimethamine + Sulfadoxine \\
\hline 5. & Ethinylestradiol + Levonorgestrel \\
\hline 6. & Neomycin + Bacitracin \\
\hline 7. & Ethinylestradiol + Norethisterone \\
\hline 8. & Lamivudine + Zidovudine \\
\hline 9. & Acriflavin + Glycerin \\
\hline 10. & Aluminium hydroxide + Magnesium hydroxide \\
\hline 11. & Lamivudine + Nevirapine + Stavudine \\
\hline 12. & Isoniazide + Thiacetazone \\
\hline 13. & Lignocaine + Epinephrine \\
\hline 14. & $\begin{array}{l}\text { Oral Rehydration Salts (sodium chloride, trisodium } \\
\text { citrate, potassium chloride, glucose) }\end{array}$ \\
\hline
\end{tabular}


Table 3: FDCs which are pharmacologically rational but not included in WHO or Indian essential medicines lists.

\begin{tabular}{|cc|}
\hline Sr. No. & Combination \\
\hline 1. & Enalapril + Amlodipine \\
\hline 2. & Telmisartan + Amlodipine \\
\hline 3. & Aspirin + Clopidogrel \\
\hline 4. & Hydrochlorothiazide + Amiloride \\
\hline 5. & Spironolactone + Furosemide \\
\hline 6. & Metformin + Repaglinide \\
\hline 7. & Metformin + Pioglitazone \\
\hline 8. & Telmisartan + Hydrochlorothiazide \\
\hline 9. & Losartan + Amlodipine \\
\hline 10. & Aspirin + Ticlopidine \\
\hline 11. & Clonidine + Hydrochlorothiazide \\
\hline 12. & Enalapril + Hydrochlorothiazide \\
\hline 13. & Atorvastatin + Ezetimibe \\
\hline 14. & Metformin + Sitagliptin \\
\hline 15. & Hydrochlorothiazide + Bisoprolol \\
\hline 16. & Atorvastatin + Fenofibrate \\
\hline 17. & Aspirin + Atorvastatin \\
\hline
\end{tabular}

\begin{tabular}{|c|c|}
\hline Sr. No & Combination \\
\hline 1. & Propranolol + Alprazolam \\
\hline 2. & Propranolol + Diazepam \\
\hline 3. & Ranitidine + Dicyclomine \\
\hline 4. & Ranitidine + Drotaverine \\
\hline 5. & Omeprazole + Domperidone \\
\hline 6. & Rabeprazole + Diclofenac \\
\hline 7. & Dicyclomine + Paracetamol + Diclofenac \\
\hline 8. & Dicyclomine + Ethylmorphine \\
\hline 9. & Dicyclomine + Valdecoxib \\
\hline 10. & Propantheline Bromide + Diazepam + DihydroxyAluminum Aminoacetate \\
\hline 11. & Propantheline + Haloperidol \\
\hline 12. & Domperidone + Paracetamol \\
\hline 13. & Aspirin + Isosorbide-5- mononitrate \\
\hline 14. & Paracetamol + Bromhexine + Chlorpheniramine maleate + Guaiphenesin + Phenylpropanolamine \\
\hline 15. & Paracetamol + Dicyclomine \\
\hline 16. & Paracetamol + Promethazine \\
\hline 17. & Paracetamol + Metoclopramide \\
\hline 18. & Alprazolam + Paracetamol \\
\hline 19. & Satranidazole + Ornidazole \\
\hline 20. & Ciprofloxacin + Tinidazole + Dicyclomine \\
\hline 21. & Ampicillin + Cloxacillin \\
\hline 22. & Amoxycillin + Cloxacillin \\
\hline 23. & Amoxycillin + Cloxacillin + Serratiopeptidase + Lactobacillus spores \\
\hline 24. & Tinidazole + Diloxanidefuroate \\
\hline 25. & Ephedrine + Theophylline + Phenobarbitone \\
\hline 26. & Phenylpropanolamine + Cetirizine + Paracetamol \\
\hline 27. & Levonorgestrol + Ethinylestradiol + Ferrous fumarate \\
\hline 28. & Gliclazide + Rosiglitazone \\
\hline 29. & Nimesulide + Paracetamol \\
\hline 30. & Enalapril + Losartan \\
\hline 31. & Norfloxacin + Tinidazole \\
\hline 32. & Diclofenac + Serratiopeptidase \\
\hline 33. & Glibenclamide + Metformin \\
\hline
\end{tabular}


Table 5: Absurd FDCs in the Indian market.

\begin{tabular}{|ll|}
\hline Sr. No. & Combination \\
\hline 1. & Dicyclomine + Dextromethorphan + Paracetamol \\
\hline 2. & Dicyclomine + Paracetamol + Chlorodiazepoxide \\
\hline 3. & Dicyclomine + Serratiopeptidase \\
\hline 4. & Amoxycillin + Serratiopeptidase + Lactobacillus \\
\hline 5. & Amoxycillin + Cloxacillin + Serratiopeptidase + Lactobacillus \\
\hline 6. & Analgin + Diazepam \\
\hline 7. & Analgin + Diazepam + Dicyclomine \\
\hline 8. & Atorvastatin + Aspirin + Caffeine \\
\hline 9. & Artesunate + Arteether + Artemether \\
\hline 10. & Ephedrine + Theophylline + Phenobarbitone \\
\hline 11. & Nimesulide + Cetirizine + Phenylephrine \\
\hline
\end{tabular}

\section{DISCUSSION}

FDCs are mushrooming in Indian pharmaceutical market since the last few years. Although DCGI had now taken up the issue seriously, lack of proper guidelines on the approval of FDCs has done no good to the concept of rational medical practice.

The rationality of a FDC should be based on certain aspects as follows. ${ }^{8}$

- The drugs in combination should act via different mechanisms

- Their pharmacokinetic profiles should be similar

- The FDC should not cause additive toxicity of the individual drugs.

Irrational FDCs not only cause more adverse drug reactions but the antibiotic FDCs are responsible for increasing the chances of resistance. These FDCs also impose unnecessary financial burden on the patients.

The SDCs have wrongly approved many irrational FDCs available in the Indian market. These approvals are illegal as any combination drug is considered to be a new drug under the Drugs and Cosmetics Act and its marketing approval has to be issued by DCGI only. ${ }^{6}$ As SDCs were lax in granting permissions, the pharmaceutical companies have obtained product license for many irrational FDCs. Once the product license is issued by SDCs, the company can market the product all over the country. ${ }^{9}$ This loophole is causing the increased availability of many FDCs in the market which have not been tested for efficacy and safety. It is unfortunate that neither the union health ministry nor the office of the DCGI is able to put a stop to this practice of marketing irrational FDCs in our country.

In our study, we came across a number of irrational FDCs (Table 4), a few of which need to be discussed for their irrationality.
1. Norfloxacin/Ciprofloxacin/Ofloxacin Tinidazole/Ornidazole

These combinations of fluoroquinolones and nitroimidazoles are widely used for all types of diarrhoea and dysentery. The practitioners ought to realise that in amoebic dysentery fluoroquinolones are useless, and in bacterial dysentery nitroimidazoles are ineffective. Both conditions may rarely co-exist, thus making the FDC irrational. $^{10}$

\section{Ampicillin/Amoxicillin + Cloxacillin}

Ampicillin/Amoxycillin are effective only against gram negative bacilli but not against beta lactamase producing staphylococci. Cloxacillin is antistreptococcal penicillin with no effect on gram negative bacilli. Both these infections rarely co-exist. Secondly, doses used in these combinations are half the usual recommended dose which may lead to therapeutic failure. ${ }^{11,12}$

3. Non-steroidal Anti-inflammatory Drugs ( NSAIDs) combinations

Adding paracetamol to another NSAID (diclofenac, aceclofenac, and ibuprofen) does not offer additional benefit, but increases the chances of nephrotoxicity. ${ }^{13}$ Combining NSAIDs with antispasmodics (dicyclomine, drotaverine) is irrational as the former has no role in colicky pain which only the latter relieve. ${ }^{14}$ Skeletal muscle relaxants (chlorzoxazone, chlormezanone, methocarbamol) increase the risk of gastric adverse effects and provide no additional benefit to the patient. Serratiopeptidase is a proteolytic enzyme supposed to relieve inflammation. This claim is not based on controlled clinical trials and FDCs containing this compound offer no additional anti-inflammatory advantage except higher cost to the patient. ${ }^{8}$

4. H2 blockers (ranitidine/famotidine) or Proton Pump Inhibitors (omeprazole/pantoprazole/ 
lansoprazole/rabeprazole) with Antiemetics (domperidone/ondansetron)

$\mathrm{H}_{2}$ blockers and proton pump inhibitors are effective in peptic ulcer and it is irrational to combine these drugs with an antiemetic as peptic ulcer is not always associated with vomiting. ${ }^{15}$

\section{Ranitidine + Dicyclomine}

Ranitidine is indicated in peptic ulcer, a condition not caused by smooth muscle spasm. Hence it is irrational to use dicyclomine in a FDC with $\mathrm{H}_{2}$ blocker.

\section{Dicyclomine + Paracetamol}

An analgesic like paracetamol will not add to the effect of dicyclomine, an antispasmodic. This FDC is not only irrational but it could be harmful to the patient. Paracetamol promotes sweating and helps in heat dissipation; on the contrary dicyclomine, an anticholinergic drug inhibits sweating. This combination can therefore, lead to dangerous elevation of body temperature. $^{8}$

7. Antibacterials (amoxycillin/cefadroxil/roxithromycin/ cephalexin/ levofloxacin) + Mucolytics (carbocisteine/bromhexine/ambroxol)

Respiratory tract infections are not always associated with thick mucus and combining these antibacterials with mucolytics for entire duration of antibacterial therapy is totally irrational.

\section{Antibacterial + Lactobacillus + /- Serratiopeptidase}

There are no controlled studies which prove the role of lactobacillus in its prevention of antibiotic-induced diarrhoea. ${ }^{16}$ Furthur addition of serratiopeptidase to this FDC makes it totally absurd.

\section{Levocetirizine/Bambuterol + Montelukast}

These FDCs are irrationally recommended for asthma. Levocetirizine, an antihistaminic has no role in asthma. ${ }^{17}$ Montelukast is recommended only as an alternative to inhaled steroids in mild persistent asthma. Bambuterol, a long acting beta- 2 agonist is indicated in moderate to severe persistent asthma. Thus, there is no indication for bambuterol and montelukast together in asthma.

\section{Glimepiride + Metformin + Voglibose}

Glimepiride is administered 10-15 minutes before a meal usually once daily, while metformin is administered after meals. Voglibose, an alpha glucosidase inhibitor has to be taken at the first bite of each meal. All the diabetic patients may not require all these three drugs and even if required, the titration of doses will be impossible in a
FDC. Importantly, time of administration of all three components is different.

\section{Flupenthixol + Melitracen}

Melitracen is an antidepressant manufactured by a Danish company but banned in Denmark itself. This drug is not individually approved in India but this FDC was approved in 1998. DCGI had recently given the pharmaceutical company 6 months time to establish the drug's safety and efficacy, ${ }^{18}$ failure of which has compelled DCGI to ban the FDC. Practitioners should hence note that it is illegal to prescribe this FDC in the future.

\section{Ramipril + Telmisartan}

Both these act on renin-angiotensin system and are associated with more adverse effects without offering any increase in benefit when combined. ${ }^{19}$

\section{Mebendazole + Pyrantelpamoate / Levamisole}

There is no known worm infestation where these two anti helminthics need to be prescribed.

\section{Antipsychotics (chlorpromazine, haloperidol, risperidone $)+$ trihexyphenidyl}

All patients receiving antipsychotic drugs do not develop extra-pyramidal toxicity and all manifestations do not respond to trihexyphenidyl. Risperidone rarely causes extra-pyramidal toxicities and does not require FDC with trihexyphenidyl.

15. Vitamin $\mathrm{B} 1+$ Vitamin $\mathrm{B} 6+$ Vitamin $\mathrm{B} 12+$ Nicotinamide + Calcium pantothenate

Vitamins B1, B6 and B12 in a FDC are banned as deficiencies of three vitamins never occur together. To avoid the ban, the other two ingredients were added by the manufacturers.

Indian pharmaceutical industry markets a number of FDCs which are pharmacologically correct but are not included in the standard drugs lists (Table 3 ).

Most of the FDCs are indicated in hypertensive and cardiac patients. These FDCs are valuable only when they are developed based on sound rational pharmacokinetic and pharmacodynamic criteria and when claims of their benefits have been supported by evidence based data and well designed clinical studies. ${ }^{20}$ Rationality of a few commonly used FDCs needs to be discussed.

\section{Aspirin + Clopidogrel}

This FDC significantly reduces collagen-induced platelet aggregation compared with individual drugs, suggesting synergism. $^{21}$ Both act via different mechanisms. In this FDC the risk of bleeding increases but the risk-benefit 
analysis shows that the benefit outweighs the risk of bleeding. $^{22}$

\section{Telmisartan + Hydrochlorothiazide}

Studies here demonstrated that activation of the reninangiotensin aldosterone system (RAAS) by hydrochlorothiazide enhances the effects of telmisartan. ${ }^{23}$ Telmisartan is an angiotensin receptor blocker and hydrochlorothiazide acts by inhibiting $\mathrm{Na}^{+} / \mathrm{Cl}^{-} \mathrm{co}-$ transport. $^{24}$

\section{Furosemide + Spironolactone}

Spironolactone, a potassium sparing diuretic counteracts hypokalemia caused by furosemide. This FDC has demonstrated high degree of efficacy as compared to individual drugs in higher $\operatorname{doses}^{25}$ and also reduces morbidity and mortality events.

\section{Amlodipine + Losartan}

As compared to individual monotherapies, this FDC has better antihypertensive efficacy. The possibility of ankle edema with amlodipine is decreased in combination with losartan. ${ }^{26}$

\section{Bisoprolol + Hydrochlorothiazide}

In this FDC, although the dose of hydrochlorothiazide is low $(6.25 \mathrm{mg})$, several clinical trials ${ }^{27,28}$ have demonstrated that this low dose is effective in control of hypertension, with decreased adverse effects with this FDC.

\section{Nebivolol + Hydrochlorothiazide}

This FDC shows an additive effect in reducing systolic and diastolic BP compared with monotherapy. This combination provides significant reduction in $\mathrm{BP}$ and prevents end organ damage. $^{29}$

We found a lot of FDCs available in the market with low or high doses. Although the components in the FDC can be rationally combined, prescribing such FDCs becomes difficult. If prescribed, the total dosage received by the patient can be less than desired or at times toxic. A few examples will prove the point:

\section{Metformin $500 \mathrm{mg}+$ Pioglitazone $30 \mathrm{mg}$}

This FDC could be rational in a patient of type 2 diabetes mellitus with insulin resistance. However, if you give this combination thrice daily for proper dose of metformin, the dosage of pioglitazone will be very high. In fact, due to adverse effects the current recommended dose of pioglitazone is only $7.5 \mathrm{mg}$ daily, and this drug has to be used with caution.

2. Spironolactone $100 \mathrm{mg}+$ Furosemide $20 \mathrm{mg}$
In this FDC, the highest dose of spironolactone is combined with the lowest dose of furosemide. Increase or decrease of one will lead to an irrational change in the other.

\section{Glimepiride $3 \mathrm{mg}+$ Metformin $850 \mathrm{mg}$}

The FDC is by itself irrational as mentioned earlier. The dose of glimepiride will be high, if the FDC is prescribed twice daily. If the patient does not respond to $4 \mathrm{mg}$ dose of glimepiride, there is no advantage of further increasing the dose.

FDCs have a lot of drawbacks if not combined rationally. A few important disadvantages are as follows: ${ }^{30}$

- Titration of doses to suit the needs of individual patient is difficult.

- The patient may need only one drug from the FDC, making the other superfluous.

- In FDCs with many drugs, a few doses may be inadequate or subtherapeutic.

- Pharmacodynamic incompatibility may render the FDC more dangerous than of any benefit.

- Adverse effects of the drugs in combination may add up to make the FDC more toxic.

- Combination product may be more expensive than the individual cost of the component drugs.

- In case of an adverse drug reaction, causality assessment of individual drugs becomes difficult in a FDC.

FDCs are mainly promoted to enhance compliance by decreasing the number of required pills. Pan et al compared a FDC to a 2-pill regimen and concluded that the FDC enhanced adherence rates by approximately $13 \%$ when compared to a 2-pill regimen. ${ }^{31}$ Increasing requirement of drugs when more than one disease is found in a patient justifies the use of FDCs to improve compliance. Consequently, a relook and rationalization is required when FDCs are prescribed to patients, so that their benefit outweighs the risk involved in prescribing unnecessary and irrational FDCs.

Irrational FDCs also impose unnecessary financial burden on the patients. Medical practitioners prescribing such FDCs may be in trouble when subjected to litigation in consumer courts as many of these FDCs are not recommended in the standard textbooks of medicine. ${ }^{11}$

There has been increase in the irrational FDCs in the recent past by leaps and bounds. The pharmaceutical companies manufacturing these FDCs are luring physicians to prescribe their products even when they are not needed by the patients. ${ }^{32}$

Although rational FDCs provide enhanced clinical benefit, most of the FDCs available in the Indian market have dubious value, and there is limited research to describe the rationality of FDCs on an individual basis. ${ }^{20}$ 
Combinations can improve effectiveness, not efficacy. Efficacy is a measure of a drugs performance in a controlled setting, like a clinical trial, whereas effectiveness is a measure of performance in real practice, where compliance is not as strictly enforced. ${ }^{33}$ The distinction is important because not all FDCs are more efficacious than the drugs given separately, but they may be more effective, because data has shown that patients are more compliant if their regimens are less complex. ${ }^{32}$

It is the need of the hour to raise our voice against the growing list of FDCs in the Indian market and try to reduce the magnitude of this problem by sensitizing the undergraduates, the interns as well as the practitioners regarding the efficacy, safety, suitability, rationality and cost benefit of FDCs available for patient use.

\section{Funding: No funding sources \\ Conflict of interest: None declared \\ Ethical approval: Not required}

\section{REFERENCES}

1. Gautam CS, Aditya S. Irrational drug combinations: need to sensitize undergraduates. Indian journal of pharmacology. 2006;38:169-70.

2. N.K. Jain, A Akarte, P T Deshmukh, P Kanojia, N Gerud, Y Akash. Rationality of FDCs: An Indian Scenario. The pharma research. 2009;(1):158.

3. WHO model list of essential medicines $16^{\text {th }}$ list. Available at: http://www.who.int/medicines/publications/essential medicines/updated sixteenth adult list en.pdf (last update March 2012).

4. National list of essential medicines 2003. Available at: http ://www.serowho.int/linkfiles/essential drugs and medicines india.pdf (accessed 3/8/2012).

5. Gulhati CM. Irrational fixed dose drug combinations: a story of profits before patients. Issues medical ethics. 2003;11:5.

6. R. Sweety Prem Kumar: Fixed Dose Combinations. Rational drugs. 2008Jan-June;31\&32:3-9.

7. Expert panel on FDCs meet in Delhi. Available at: www.indswiftltd.com/view_news.php?id=826 (accessed on 12/4/2013).

8. Amitav. S: Indian markets fixation with FDCs (editorial) rational drug bulletin. 2002;12:1.

9. B G Jayasheel. Regulatory requirements for marketing FDCs. Perspect Clin Res. 2010;1(4):1203.

10. Chakraborti A. Prescription of FDC drugs for diarrhea. Indian Journal of medical Ethics. 2007;4:165-7.

11. C.S Gautam, L. Saha. FDCs- rational or irrational: a view point. British Journal of Clinical Pharmacology. 2008May;65(s):795-6.

12. Sreedhar D. Menthan D, Jawodia, V.S Ligade, S Mohapatra, R Ganguly, N.V Dupa. FDCs: rational or irrational? Current status. 2008;95(5):581-3.
13. Gulhati CM: Monthly Index of Medical Specialities, India. 2005;25:81-94.

14. Burke A, Smyth E, Gerald GAF. Analgesicantipyretic agents; pharmacotherapy of gout. Goodman and Gilman's: The Pharmacological basis of Therapeutics. New York. McGraw- Hill; Jadav $\mathrm{Sp}$, Parmen DM. critical appraisal of irrational drug combinations: a cell for awareness in undergraduate medical students. Journal of pharmacotherapy. 2011;2:45-8.

15. Soll AH. Medical treatment of peptic ulcer disease: practical guidelines. JAMA. 1996;275:622.

16. Sweetman S.C. (editor) Lactic acid producing organisms. Martindale- the complete drug Reference, $35^{\text {th }}$ edition. Pharmaceutical press. 2007.

17. Main PL, LJ. Levocetirizine: a review of its use in the management of allergic rhinitis and skin allergies. Drugs. 2006;66:973-96

18. Alex J. India may ban sale of flupenthixol melitracen combination drug. Pharmacological convention. 2013Jan17.

19. On target investigators, Yusuf S, Teo KK, Pogue J, Dyel L, Coplain L, et al. Telmisartan, ramipril, or both in patients at high risk for vascular events. New England Journal of Medicine. 2008;258:1547-59.

20. Peuda J, Tiwari P, Uppal R. evaluation of the rationality of some FDCs: focus on antihypertensive drugs. Indian Journal of Pharmacology. 2006;68:649-53.

21. Diener HC, Bogousslausky J, Brass LM, Cimminello C, Lsibn L, Kaste M, Leys D, MetinsGuriu J, Rupprecht. Lancet. 2004;24:331.

22. More PM, Michel B. Is the FDC of telmisartan and HCTZ a good approach to treat hypertension? Vascular health and risk management. 2007:265-78.

23. Bhattacharya SK, Sen P, Roy A, Pharmacology, Elsevier, New Delhi 2. 2003:561-5.

24. Anastasios M, Maria S, Dimitris PP. Resistant hypertension workup and approach to treatment. International Journal of Hypertension. 2011; 2011:1-10.

25. Osvaldo K, Wilte O, Decio N, Joao CR, Marco AMG, Natalino S, Gilson SF, Ernesto D, Artur BR. The "LOTHAR" study: Evaluation of efficacy and tolerability of the FDC of Amlodipine and Losartan in the treatment of essential hypertension. Arquivas de Cardiologia. 2006;1:86.

26. Frishman W, Burnis JF, Mrocek WJ, Weir MR, Atemayehu D, Simmon 15, Chensy, Bryzinski BS. Journal of Clinical Pharmacology. 1995;35:182.

27. Benetos A, Adamopados C, Argyriadis P, Been K, Consoli S, Safar MJ. Hypertension. 2002;20:521.

28. Stone Malacio, Nob HCR. FDC for effective antihypertensive therapy. High blood pressure cardiovascular prevention. 2008;15(2):25-84.

29. Rational use of medicines. Good pharmacy practice I.P.A. C.D.S.C.O.- W.H.O India office. Available at: http://www.whoindia.org/lintfiles/GPP Rational use of medicines.pdf (Accessed on 3/8/2010). 
30. F. Pan, M.E. Chernew, A Mark Fendrick. Impact of FDC drugs on adherence to prescription medications. J. Gen Internal Med. 2008;23(5):611-4.

31. Sreedhar O, Subramanian G, Udipa N. combination drugs are they rational? 2006;91:406.

32. Podolsky SH, Greene JA. Combination drugs- Hype and hope: New England Journal of Medicine. 2011;356(6):488-91.
33. Glasgow RE, Lichtenstein E, Mercus AC. Why don't we see more translation of health promotion research to practice? Rethinking the efficacy to effectiveness transition. American Journal of Public Health. 2003;93(8):1261-7.

doi:10.5455/2319-2003.ijbcp20140212

Cite this article as: Nigam MP, Fernandes VLG, Rataboli PV. Fixed dose combinations- to prescribe or not to prescribe: a dilemma of medical profession. Int J Basic Clin Pharmacol 2014;3:105-13. 